\title{
EFFECT OF FOLK DANCE TRAINING ON BLOOD OXIDATIVE STRESS LEVEL, LIPIDS, AND LIPOPROTEINS
}

\author{
BORA OKDAN ${ }^{1}$, GULBIN RUDARLI NALCAKAN ${ }^{2}$, ECE ONUR ${ }^{3}$, ARZU ORAN $^{3}$, MESUT NALCAKAN $^{4}$
}

\author{
${ }^{1}$ Ege University, State Turkish Music Conservatory, Department of Turkish Folk Dances, Izmir, Turkey \\ ${ }^{2}$ Ege University, Faculty of Sport Science, Department of Coaching Education, Izmir, Turkey \\ ${ }^{3}$ Celal Bayar University, Faculty of Medicine, Department of Biochemistry, Manisa, Turkey \\ ${ }^{4}$ Esrefpasa Hospital, Department of Sports Health, Izmir, Turkey
}

\begin{abstract}
Mailing address: Gulbin Rudarli Nalcakan, Ege University, Faculty of Sport Science, Department of Coaching Education, 12 Gençlik Street, 35040 Bornova, Izmir, Turkey, tel.: +90 232 3425714, fax: +90 232 3399000, e-mail: gulbinrn@gmail.com
\end{abstract}

\begin{abstract}
Introduction. Folk dance is a form of physical activity which helps develop the ability to use the whole body in a coordinated way with music, and folk dancers' characteristics vary according to the particular type of dance practised in a given geographic region. The aims of the study were to evaluate the effects of 12-week folk dance training on blood oxidative stress level, lipids, lipoproteins, as well as muscle damage markers and to define some physical and physiological properties of folk dancers. Material and methods. Thirty-eight healthy male folk dancers aged 21-28 years having an average of 11 years of dance training experience voluntarily participated in the study. All of the physical and physiological measurements and the blood analysis were performed twice, before and after the training period which focused on different regional dances (Caucasus, Bar, Zeybek, Spoon Dance, Thracian dances, and Horon). The training was done 2 hours per day (a total of 10 hours a week), during a 12-week-long period. Results. All the blood parameters were found to be within the specified reference ranges. The training programme had no significant effect on the blood lipid profile, whereas it was found to have positive effects on body fat ( $\mathrm{p} \leq 0.012)$, peak oxygen consumption $\left(\mathrm{VO}_{2 \text { peak }} ; \mathrm{p}=0.000\right)$, muscle damage markers (creatine kinase, $\left.\Delta \%=-19.6\right)$, and total antioxidant capacity ( $\mathrm{p} \leq$ 0.002). Conclusions. Regular folk dance training was found to have positive effects on body fat, $\mathrm{VO}_{2 \text { peak, }}$, blood total antioxidant capacity, and muscle damage markers. Based on these results, the community should be encouraged to perform folk dance as a recreational physical activity, and public awareness should be raised about the health benefits of practising folk dances.
\end{abstract}

Key words: body fat, creatine kinase, folk dancer, heart rate, high-density lipoprotein, total antioxidant capacity

\section{Introduction}

Increased reactive oxygen species (ROS) in an organism may have a positive effect on the immune system, but their increased levels induce lipid, protein, and DNA oxidation, which in turn causes cell damage via enzyme inactivation, lipid peroxidation, and protein and lipoprotein oxidation [1]. These radicals are rapidly destroyed by antioxidant defence systems in a normal organism. However, if radical production exceeds the antioxidant capacity of the tissue, oxidative stress occurs. Increases in ROS production depend on the intensity and duration of exercise [2] and are likely to have a negative impact on physical performance, causing muscle fatigue, muscle damage, muscle pain, and overtraining [3]. It has been reported that the increase in the production of ROS during exercise results from either increased electron flow in the mitochondrial electron transport system during aerobic exercises or from the activation of an ischemiareperfusion-induced xanthine oxidase pathway during anaerobic exercises [1].

The general view is that tissue damage increases as a result of significant increases in oxygen consumption during intense exercise, no matter what the training level is, whereas plasma antioxidants decrease and free radical production increases. Yet, resistance occurs against oxidative stress and antioxidant enzymes increase through adaptation as a result of regular exercise [2].

The measurement of total antioxidant capacity gives more comprehensive information about the blood antioxidant level than measuring antioxidants separately [4]. The magnitude of the oxidative stress which might occur during exercise does not only depend on free radical production, but it also depends on a person's antioxidant defence capacity. For that reason, it is necessary to measure both the total antioxidant capacity (TAC) and total oxidant status (TOS) parameters and to calculate the oxidative stress index $(\mathrm{OSI}=\mathrm{TOS} / \mathrm{TAC})$ which reflects oxidative balance [4].

During exercise, parameters such as oxygen consumption and heart rate (HR) increase proportionally to exercise intensity. Therefore, HR may be used as an indicator of physiological stress during exercise and may be applied to determine $\mathrm{VO}_{2}$ or

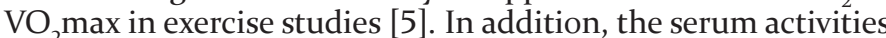
of skeletal muscle enzymes such as creatine kinase (CK), lactate dehydrogenase (LDH), alanine aminotransferase (ALT), and aspartate aminotransferase (AST) have been used as indicators of skeletal muscle damage and muscle functional status in healthy people [3].

Sedentary lifestyle is an independent risk factor for coronary heart diseases (CHD), but regular exercise has a protective 
function against atherosclerosis and CHD. It is a well-known fact that there is a relationship between the frequency, duration, and intensity of exercise and reducing CHD risk [6]. It is reported that regular aerobic exercise decreases low-density lipoprotein cholesterol (LDL-C), total cholesterol (TC), and triglyceride (TG) levels and increases high-density lipoprotein cholesterol (HDL-C) levels [6].

Regular folk dance training enhances body coordination with music. Furthermore, it helps to gain precious movement skills according to the rhythm of the music [7]. Dance training is aimed to improve techniques, skills, and the aesthetic factor and to combine these components together with the physical and physiological capabilities of dancers. It has been reported that regular dance trainings, performed in various duration and intensity, according to different regional traditions, have positive impacts, at different levels, on motor skills such as strength, power, agility, and endurance [7-9]. However, the effects of folk dance training on the oxidative stress level are unclear. The oxidative stress level has been investigated in only one study available in the literature (on the effects of ballet dance) [10].

The aim of this study is to investigate the effects of 12 -week folk dance training on blood oxidative stress indicators and blood lipid and lipoprotein levels in folk dancers. It is also aimed to determine the effect of folk dance training on muscle damage markers and some physical and physiological characteristics of the dancers. There has been no research published about this subject in folk dancers so far. Outlining the dancers' profile that includes the physical and physiological stress levels in the current study may be beneficial, as it may deliver information about the requirements of the sport and contribute to improving the quality and quantity of the training to be planned.

\section{Material and methods}

This is a cross-sectional design study. It was approved by a local medical research ethics committee and was undertaken in compliance with the Helsinki Declaration.

The study involved healthy male folk dancers $(n=38)$ with minimum 5-year dance training aged from 21 to 28 years who were not obese and did not use any medication or supplements. The training period was started after a 3-month off-season, and it lasted a total of 12 weeks, during which different regional folk dances (Caucasus, Bar, Zeybek, Spoon Dance, Thracian dances, and Horon) were practised. Each session was 2 hours long, and the dances were practised in a different order. The training was composed of intermittent exercises of different durations, including coordinated sequences of both static and dynamic whole-body muscle actions, interspersed by short rest periods. The mean weekly training load over the 12 weeks was $66 \%$ HRmax (55-73\%); the mean load in a training session was between 108-143 bpm, and the minimum and maximum HR values measured were 90 and 189 bpm, respectively. The training sessions were performed in the presence of expert supervisors and were composed of a general warm-up (10 min for jogging and whole-body dynamic movements), followed by a specific warm-up with regional dance steps, the main phase (90 min for a combination of technical skill repetition and technical improvement practices and choreography practice and rehearsals), and a cooling phase (10 min for jogging and stretching).

The participants were instructed not to attend physical activities other than the 2-hour trainings performed every day during the 12 -week training period, not to change their diets, not to do any exercise for two days before their testing sessions, and to pay attention to their sleep.

The baseline data were acquired on a Monday morning prior to the start of the first dance training session after a 60-day holiday period. The post-training data collection was performed 12 weeks later, $48 \mathrm{~h}$ after the final training session.

The dancers were examined by a physician. The following physical measurements were taken: height, body mass, body fat $(\mathrm{BF} \%)$, sum of skinfold thicknesses (SS) at 8 sites, and body mass index (BMI), and some physiological measurements were performed during the training sessions, which included maximal oxygen uptake $\left(\mathrm{VO}_{\text {2peak }}\right)$ and $\mathrm{HR}$. In addition to performing haemogram analysis, including leucocyte (WBC), erythrocyte (RBC), haemoglobin ( $\mathrm{Hb})$, haematocrit (Hct), and thrombocyte (Plt) counts and mean corpuscular volume (MCV), to obtain knowledge about the general health of the dancers, oxidative stress indicators (TAC, TOS, and OSI), lipid and lipoprotein levels (TC, TG, HDL-C, and LDL-C), as well as muscle damage markers (LDH, CK, ALT, and AST) were measured in blood samples taken before and after the 12-week training period.

Height and body mass measurements were made with minimal clothes using electronic medical scales (Seca 769, Hamburg, Germany), and the body mass index (BMI) was calculated. Total body fat was assessed using a skinfold caliper (Holtain, Crymych, UK) at 8 sites: the triceps, biceps, subscapular, pectoral, suprailiac, abdominal, quadriceps, and calf skinfolds were measured. The data were reported as SS in $\mathrm{mm}$ by adding the measured skinfold thicknesses and body fat percentage according to the formula developed by Ratamess from the American College of Sports Medicine [11]. $\mathrm{VO}_{2 \text { peak }}$ was defined as the accepted result of a maximal oxygen uptake test without a validation test. The Cooper test was used to measure endurance capacity indirectly and estimate $\mathrm{VO}_{2 \text { peak }}$ for a distance completed in $12 \mathrm{~min}$, using the following formula: $\mathrm{VO}_{2 \text { peak }}=($ distance $(\mathrm{m})$ - 504.9)/44.73. Its correlation with the laboratory-determined oxygen consumption data was 0.897 [6]. HR measurement was performed using a telemetrical pulse counter system (Activio $\mathrm{AB}$, Stockholm, Sweden) which transmits data wirelessly and is connected to a computer with a chest strap which was worn by each of the dancers in order to detect the intensity of the training only in the main phase of the training.

After 8 hours of overnight fasting, venous blood samples were collected for biochemical analyses into evacuated plain tubes from all the participants in sitting position. This was done by a nurse in the biochemistry laboratory of the Sport Science Department between 9 a.m. and 10 a.m. in the morning. The vacutainer tubes $(10 \mathrm{~mL})$ were held at room temperature for 30 min and then centrifuged for $15 \mathrm{~min}$ at $2000 \mathrm{~g}$ (Nuve NF 200, Ankara, Turkey). The sera were removed and kept at $-20^{\circ} \mathrm{C}$ until analysis. The samples for haemogram evaluation were analysed in EDTA tubes in 3-4 hours on the same day using an Automatic Hematology Analyzer (BC-3200 Mindray, Shenzhen, China) in a private laboratory. Serum TAC and TOS levels were analysed spectrophotometrically with a commercial kit (Rel Assay Diagnostics, Gaziantep, Turkey) by means of an autoanalyser (Siemens Advia 1800, Germany), using an automated colorimetric method. OSI was calculated using these data, based on the following formula: OSI $=$ TOS $\left(\mu \mathrm{mol} \mathrm{H}_{2} \mathrm{O}_{2} \mathrm{Eq} / \mathrm{L}\right) / \mathrm{TAC}(\mu \mathrm{mol}$ Trolox Eq/L) $\times 100$. CVs for intra- and inter-assay of the TAC and TOS kits were lower than 3.0\%. Serum TC, HDL-C, TG levels and LDH, CK, ALT, and AST were analysed with a Cobas-Integra-800 chemistry autoanalyser (Roche Diagnostic Systems, Mannheim, Germany) using an enzymatic colorimetric method. LDL-C levels were calculated according to Friedewald for- 
mula. Percentage changes in the volumes of plasma (PV) were calculated using Dill and Costill's (1974) method [12] and corrected for significant PV differences (4.4\%). All the biochemical parameters were determined within one month.

The data were analysed using SPSS 16.0 (SPSS Inc., Chicago, IL), following normality (Shapiro-Wilk) testing. If the data conformed to normal distribution, paired sample t-tests were used to compare test values before and after the training period, and Wilcoxon signed-rank tests were used if the data did not conform to normal distribution. The data evaluated non-parametrically have been indicated with a ' $¥$ ' sign in the tables. The effect size of the difference between the data was described using Cohen's d $(<0.2=$ trivial effect $; 0.2 \leq \mathrm{d}<0.5=$ small effect; 0.5 $\leq \mathrm{d}<0.8=$ moderate effect; $\mathrm{d} \geq 0.8=$ large effect), and the manufacturer's recommendations for the reference range of blood parameters were marked using ' $\&$ '. The data were presented as the mean $\pm \mathrm{SD}$, minimal value, maximal value, and percentage change in means $(\Delta \%)$. Significance was established at the level of $\mathrm{p} \leq 0.05$.

\section{Results}

The physical and physiological data of 38 folk dancers measured before (1) and after (2) the training period are shown in table 1 . There were no significant training effects on the physical properties (body mass and BMI) of the folk dancers, and significant decreases were detected in SS $(p=0.012)$ measured at 8 sites and $\mathrm{BF} \%(\mathrm{p}=0.000)$. The mean $\mathrm{VO}_{\text {, }}$ measured using the Cooper test increased significantly $(\mathrm{p}=0.000)$.

In addition, the haemogram analysis results of the dancers before and after the training period were found to be within normal reference ranges, and a certain decrease occurred in $\mathrm{Hb}$ $(\mathrm{g} / \mathrm{dL})$. Also, a significant increase was found in MCV (fL) (p = 0.000) (tab. 2).

Table 1. Physical and physiological characteristics of the folk dancers $(\mathrm{n}=38)$ before $(1)$ and after $(2)$ the training period

\begin{tabular}{|c|c|c|c|c|c|}
\hline & & Min & Max & Mean & $\pm S D$ \\
\hline \multicolumn{2}{|l|}{ Age (years) } & 21.0 & 28.0 & 24.5 & 2.10 \\
\hline \multicolumn{2}{|c|}{ Dance training background (years) } & 5.0 & 16.0 & 11.2 & 3.13 \\
\hline \multicolumn{2}{|l|}{ Height (cm) } & 160 & 192 & 178 & 5.87 \\
\hline \multirow{2}{*}{ Body mass $(\mathrm{kg}) ¥$} & 1 & 47.0 & 91.0 & 75.0 & 10.1 \\
\hline & 2 & 49.0 & 90.0 & 73.0 & 9.7 \\
\hline \multirow{2}{*}{$\operatorname{BMI}\left(\mathrm{kg} / \mathrm{m}^{2}\right)$} & 1 & 18.4 & 28.4 & 23.6 & 2.70 \\
\hline & 2 & 18.5 & 28.3 & 23.5 & 2.55 \\
\hline \multirow{2}{*}{$\begin{array}{l}\text { Cooper test distance } \\
\text { (m) } ¥\end{array}$} & 1 & 1400 & 2510 & 2173 & 262 \\
\hline & 2 & 1600 & 3000 & $2456^{*}$ & 268 \\
\hline \multirow{2}{*}{$\mathrm{VO}_{2 \text { peak }}\left(\mathrm{ml} \cdot \mathrm{kg} \cdot \mathrm{min}^{-1}\right) ¥$} & 1 & 20.0 & 44.8 & 37.1 & 5.96 \\
\hline & 2 & 24.5 & 55.8 & $43.6^{*}$ & 6.01 \\
\hline \multirow{2}{*}{$\mathrm{SS}(\mathrm{mm}) ¥$} & 1 & 37.0 & 153 & 91.3 & 31.7 \\
\hline & 2 & 36.0 & 140 & $84.1^{*}$ & 28.2 \\
\hline \multirow{2}{*}{$\mathrm{BF}(\%) ¥$} & 1 & 9.70 & 23.1 & 16.9 & 4.11 \\
\hline & 2 & 9.70 & 21.2 & $14.6^{*}$ & 3.47 \\
\hline
\end{tabular}

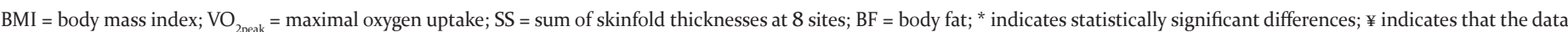
were evaluated non-parametrically.

Table 2. Haemogram analysis of the folk dancers before (1) and after (2) the training period

\begin{tabular}{|c|c|c|c|c|c|c|c|}
\hline & & Ref. range \& & Mean & $\pm S D$ & $\Delta \%$ & $\mathrm{p}$ & d \\
\hline \multirow{2}{*}{ WBC $\left(\mathrm{K} / \mathrm{mm}^{3}\right)$} & 1 & \multirow{2}{*}{$4-10$} & 7.33 & 1.47 & \multirow{2}{*}{4.23} & \multirow{2}{*}{0.111} & \multirow{2}{*}{0.191} \\
\hline & 2 & & 7.64 & 1.77 & & & \\
\hline \multirow{2}{*}{$\mathrm{RBC}\left(\mathrm{M} / \mathrm{mm}^{3}\right) ¥$} & 1 & \multirow{2}{*}{$4.4-5.8$} & 5.45 & 0.34 & \multirow{2}{*}{1.68} & \multirow{2}{*}{0.179} & \multirow{2}{*}{0.253} \\
\hline & 2 & & 5.36 & 0.37 & & & \\
\hline \multirow{2}{*}{$\mathrm{Hb}(\mathrm{g} / \mathrm{dL})$} & 1 & \multirow{2}{*}{$14-18$} & 16.6 & 0.87 & \multirow{2}{*}{5.42} & \multirow{2}{*}{$0.000^{*}$} & \multirow{2}{*}{0.977} \\
\hline & 2 & & 15.7 & 0.97 & & & \\
\hline \multirow{2}{*}{ Hct (\%) } & 1 & \multirow{2}{*}{$\% 42-52$} & 47.6 & 2.57 & \multirow{2}{*}{1.68} & \multirow{2}{*}{0.141} & \multirow{2}{*}{0.272} \\
\hline & 2 & & 46.8 & 3.28 & & & \\
\hline \multirow{2}{*}{ Plt $\left(\mathrm{K} / \mathrm{mm}^{3}\right) ¥$} & 1 & \multirow{2}{*}{$150-450$} & 214 & 39.8 & \multirow{2}{*}{2.80} & \multirow{2}{*}{0.486} & \multirow{2}{*}{0.159} \\
\hline & 2 & & 220 & 35.5 & & & \\
\hline \multirow{2}{*}{ MCV (fL) } & 1 & \multirow{2}{*}{$80-95$} & 87.6 & 3.86 & \multirow{2}{*}{3.20} & \multirow{2}{*}{$0.000^{*}$} & \multirow{2}{*}{0.625} \\
\hline & 2 & & 90.4 & 5.03 & & & \\
\hline
\end{tabular}

$\mathrm{WBC}=$ leucocyte count; $\mathrm{RBC}=$ erythrocyte count $\mathrm{Hb}=$ haemoglobin; $\mathrm{Hct}=$ haematocrit; $\mathrm{Plt}=$ thrombocyte count; $\mathrm{MCV}=$ mean corpuscular volume; $\mathrm{SD}=$ standard deviation; $\Delta \%=$ percentage change in means; $\mathrm{d}=$ Cohen's $\mathrm{d}(<0.2=$ trivial effect; $0.2 \leq \mathrm{d}<0.5=$ small effect; $0.5 \leq \mathrm{d}<0.8=$ moderate effect; $\mathrm{d} \geq 0.8=$ large effect); * indicates statistically significant differences; $¥$ indicates that the data were evaluated non-parametrically; \& shows manufacturer's recommendations for the reference range of blood parameters. 
Table 3. Blood lipid profile of the folk dancers before (1) and after (2) the training period

\begin{tabular}{|c|c|c|c|c|c|c|c|}
\hline & & Ref. range \& & Mean & \pm SD & $\Delta \%$ & $p$ & d \\
\hline \multirow{2}{*}{$\mathrm{TC}(\mathrm{mg} / \mathrm{dl}) ¥$} & 1 & \multirow{2}{*}{$<200$} & 174 & 35.1 & \multirow{2}{*}{3.45} & \multirow{2}{*}{0.482} & \multirow{2}{*}{0.170} \\
\hline & 2 & & 180 & 35.6 & & & \\
\hline \multirow{2}{*}{ HDL-C $(\mathrm{mg} / \mathrm{dl}) ¥$} & 1 & \multirow{2}{*}{$>35$} & 35.2 & 10.2 & \multirow{2}{*}{6.82} & \multirow{2}{*}{0.293} & \multirow{2}{*}{0.235} \\
\hline & 2 & & 37.6 & 10.2 & & & \\
\hline \multirow{2}{*}{ LDL-C (mg/dl) } & 1 & \multirow{2}{*}{$<130$} & 116 & 34.4 & \multirow{2}{*}{11.2} & \multirow{2}{*}{$0.015^{\star}$} & \multirow{2}{*}{0.452} \\
\hline & 2 & & 129 & 21.7 & & & \\
\hline \multirow{2}{*}{ TG (mg/dl) $¥$} & 1 & \multirow{2}{*}{$40-130$} & 113 & 57.6 & \multirow{2}{*}{10.6} & \multirow{2}{*}{0.280} & \multirow{2}{*}{0.026} \\
\hline & 2 & & 125 & 63.9 & & & \\
\hline
\end{tabular}

$\mathrm{TC}=$ total cholesterol; HDL-C $=$ high-density lipoprotein cholesterol LDL-C = low-density lipoprotein cholesterol; $\mathrm{TG}=$ triglyceride; $\mathrm{SD}=$ standard deviation; $\Delta \%=$ percentage change in means; $\mathrm{d}=$ Cohen’s $\mathrm{d}(<0.2=$ trivial effect; $0.2 \leq \mathrm{d}<0.5=$ small effect; $0.5 \leq \mathrm{d}<0.8=$ moderate effect; $\mathrm{d} \geq 0.8=$ large effect); * indicates statistically significant differences; $¥$ indicates that the data were evaluated non-parametrically; \& shows manufacturer's recommendations for the reference range of blood parameters.

Table 4. Muscle damage markers of the folk dancers before (1) and after (2) the training period

\begin{tabular}{|c|c|c|c|c|c|c|c|}
\hline & & Ref. range \& & Mean & $\pm S D$ & $\Delta \%$ & $p$ & d \\
\hline \multirow{2}{*}{ AST (U/L) ¥ } & 1 & \multirow{2}{*}{$0-35$} & 13.8 & 3.35 & \multirow{2}{*}{3.62} & \multirow{2}{*}{0.396} & \multirow{2}{*}{0.152} \\
\hline & 2 & & 14.3 & 3.20 & & & \\
\hline \multirow{2}{*}{ ALT (U/L) } & 1 & \multirow{2}{*}{$0-45$} & 7.88 & 3.17 & \multirow{2}{*}{-16.4} & \multirow{2}{*}{$0.028^{*}$} & \multirow{2}{*}{0.403} \\
\hline & 2 & & 6.77 & 1.80 & & & \\
\hline \multirow{2}{*}{ LDH (U/L) } & 1 & \multirow{2}{*}{$0-248$} & 121 & 16.7 & \multirow{2}{*}{9.91} & \multirow{2}{*}{$0.023^{*}$} & \multirow{2}{*}{0.607} \\
\hline & 2 & & 133 & 22.4 & & & \\
\hline \multirow{2}{*}{ CK (U/L) $¥$} & 1 & \multirow{2}{*}{$<174$} & 89.1 & 47.3 & \multirow{2}{*}{-19.6} & \multirow{2}{*}{0.069} & \multirow{2}{*}{0.308} \\
\hline & 2 & & 74.5 & 47.4 & & & \\
\hline
\end{tabular}

AST = aspartate aminotransferase; $\mathrm{ALT}=$ alanine aminotransferase $\mathrm{LDH}=$ lactate dehydrogenase; $\mathrm{CK}=$ creatine kinase; $\mathrm{SD}=$ standard deviation; $\Delta \%=$ percentage change in means; $\mathrm{d}=$ Cohen's $\mathrm{d}\left(<0.2=\right.$ trivial effect; $0.2 \leq \mathrm{d}<0.5=$ small effect; $0.5 \leq \mathrm{d}<0.8=$ moderate effect; $\mathrm{d} \geq 0.8=$ large effect); ${ }^{*}$ indicates statistically significant differences; $¥$ indicates that the data were evaluated non-parametrically; \& shows manufacturer's recommendations for the reference range of blood parameters.

Table 5. Oxidative stress and antioxidant markers of the folk dancers before (1) and after (2) training period

\begin{tabular}{|c|c|c|c|c|c|c|c|}
\hline & & Ref. range \& & Mean & $\pm \mathrm{SD}$ & $\Delta \%$ & $p$ & d \\
\hline \multirow{2}{*}{ TAC 1 A ( $\mu$ mol Trolox Eq/L) } & 1 & \multirow{2}{*}{$1.32-2.12$} & 1.31 & 0.49 & \multirow{2}{*}{55.0} & \multirow{2}{*}{$0.000^{*}$} & \multirow{2}{*}{1.425} \\
\hline & 2 & & 2.03 & 0.52 & & & \\
\hline \multirow{2}{*}{ TOS $1\left(\mu \mathrm{mol} \mathrm{H}_{2} \mathrm{O}_{2} \mathrm{Eq} / \mathrm{L}\right)$} & 1 & \multirow{2}{*}{$5.12-$} & 5.12 & 2.07 & \multirow{2}{*}{7.22} & \multirow{2}{*}{0.674} & \multirow{2}{*}{0.161} \\
\hline & 2 & & 5.49 & 2.49 & & & \\
\hline \multirow{2}{*}{ OSI $1(\%) ¥$} & 1 & & 4.31 & 2.08 & \multirow{2}{*}{48.1} & \multirow{2}{*}{$0.002^{*}$} & \multirow{2}{*}{0.718} \\
\hline & 2 & & 2.91 & 1.81 & & & \\
\hline
\end{tabular}

$\mathrm{TAC}=$ total antioxidant capacity $\mathrm{TOS}=$ total oxidant status; $\mathrm{OSI}=$ oxidative stress index; $\mathrm{SD}=$ standard deviation; $\Delta \%=$ percentage change in means; $\mathrm{d}=$ Cohen's $\mathrm{d}(<0.2=$ trivial effect; $0.2 \leq \mathrm{d}<0.5$ = small effect; $0.5 \leq \mathrm{d}<0.8=$ moderate effect; $\mathrm{d} \geq 0.8=$ large effect); * indicates statistically significant differences; $¥$ indicates that the data were evaluated nonparametrically; \& shows manufacturer's recommendations for the reference range of blood parameters.

Table 6. Heart rate (pulse/min) of the folk dancers during folk dance exercises according to various geographic regions

\begin{tabular}{|c|c|c|c|c|c|c|}
\hline \multicolumn{2}{|c|}{ Dances and regions } & Min & Max & Mean & $\pm S D$ & $\%$ HRmax \\
\hline \multicolumn{2}{|c|}{ Bar (Erzurum) } & 101 & 168.7 & 128.8 & 15.0 & 0.66 \\
\hline \multicolumn{2}{|c|}{ Thracian dance (Trakya) } & 110 & 179.5 & 137.1 & 15.4 & 0.70 \\
\hline \multicolumn{2}{|c|}{ Horon (Karadeniz) } & 118 & 188.9 & 143.2 & 14.7 & 0.73 \\
\hline \multicolumn{2}{|c|}{ Caucasus (Kafkasya) } & 105 & 182.7 & 135.1 & 17.8 & 0.69 \\
\hline \multicolumn{2}{|c|}{ Spoon Dance (Akdeniz) } & 95 & 158.2 & 122.9 & 13.2 & 0.63 \\
\hline \multirow{2}{*}{ Zeybek (Ege) } & Kıvrak & 90 & 168.5 & 119.6 & 13.7 & 0.61 \\
\hline & Agir & 90 & 162.6 & 107.9 & 10.7 & 0.55 \\
\hline
\end{tabular}

$\mathrm{SD}=$ standard deviation; \% HRmax = maximal HR percentage. 
The blood lipid profiles were found to be within normal reference ranges before and after the training period in the current study, except the increase in LDL-C ( $<<0.015)$ (tab. 3).

The skeletal muscle damage indicators of the folk dancers were within reference ranges, and we observed significant differences in CK $(\Delta=-19.6 \%)$, ALT, and LDH activities $(\mathrm{p} \leq 0.05)$ as a result of the training (tab. 4$)$.

The OSI value of the folk dancers calculated via serum TAC and TOS is presented in table 5. The total antioxidant capacities (TAC and OSI) of dancers improved significantly as a result of the 12 -week folk dance training ( $\mathrm{p} \leq 0.01)$.

Table 6 shows the minimal and maximal values of HR, mean HR, and maximal HR percentage (\% HRmax) measured during the folk dance exercises.

\section{Discussion}

Folk dance is one of Turkey's cultural elements based on performance. It has a wide range of movement and necessitates that dancers should have specific fitness-based characteristics depending on the speed and duration of the dances. Since there is a lack of information on the physical and physiological effects of folk dances on human health [13], the current study was initiated to test the effects of 12 -week folk dance training on the oxidative stress level, lipids and lipoproteins, muscle damage indicators, and some physical and physiological characteristics of the folk dancers.

The data identifying the dancers' physical and physiological characteristics (tab. 1) had a wide range (height: 160-192 cm; body mass: 49-90 kg; BMI: 18.5-28.3; SS: 36-140 mm; BF\%: 9.7-

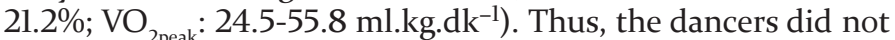
have any common specific characteristics, neither as a whole group nor in groups practising particular types of dance, despite having an average of 11 years of experience in folk dancing. It is known that the movement sequence of each sport is different, and either the different movement sequence or the metabolic response required by those sequences have an influence on the physical and physiological characteristics of the athletes. In addition, it is one of the approved selection criteria that physical properties should be in accordance with the characteristics of a particular type of dance [14]. The study results indicate that no criteria concerning certain 'physical and physiological characteristics' need to be fulfilled for a person to practise folk dances.

However, significant improvement has been found in the data regarding the $\mathrm{VO}_{2 \text { peak }}$ value $(\Delta \%=18)$, sum of skinfold thicknesses (SS, $\Delta \%=9)$, and body fat $(\mathrm{BF} \%, \Delta \%=16)$ at the end of 12-week training period (tab. 1). Similarly to these results, some other authors have shown that the characteristics of movement in folk dance have a significant effect on the formation of physical fitness and mobility and also help decrease body mass by reducing body fat [7-9, 13, 15].

In two studies, where Halay and Horon groups [9] and Zeybek and Horon groups [16] were compared, it has been reported that body fat and circumference values are significantly lower in the Horon groups. These results are due to the fact that the Horon dance consists of movements with high frequency and intensity [9].

In studies evaluating the effects of regular folk dance exercise on some physical and physiological characteristics, positive results have been reported: 12-week folk dance training was found to have significant impacts on body mass, body fat, anaerobic and aerobic power, and leg power parameters in men [13], while a 10-week aerobic-based folk dance training period decreased body mass and BMI in female and male participants, in addition to improving the range of motion of the arms as well as balance, agility, leg power, and cardiorespiratory endurance. Low-intensity dance training programmes were observed to have positive effects on aerobic capacity, heart rate in submaximal exercise, and body composition [13, 15, 17]. Similarly, 17 weeks of ballet training have been shown to cause a decrease in the relative body fat and an increase in the lean body mass of ballerinas. This result concerning physical improvement may be associated with the nature of classical and contemporary ballet dances, which are widely acknowledged as predominantly intermittent exercises, with performance imposing high demands on the aerobic and anaerobic systems [18].

Although regional attitude and aesthetic appearance continue to be important in folk dances, endurance capability is also a very important factor in a dancer's performance. Aerobicbased training that improves the cardiovascular system in Turkish folk dances is generally performed by repeating the stepping for long training hours. The mean values of $\mathrm{VO}_{2 \text { peak }}$ found in the current study are in accordance with the previous values report-

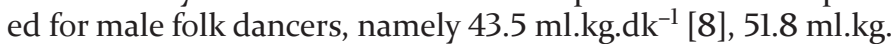
$\mathrm{dk}^{-1}$ [19], and $45.3 \mathrm{ml} . \mathrm{kg} \mathrm{dk}^{-1}$ [20]. However, the $\mathrm{VO}_{2 \text { eak }}$ values of male dancers of 30 top class dancesport couples (12 Standard, 7 Latin American, and 11 Ten Dance) were higher (59.2-60.9 ml.kg. $\mathrm{dk}^{-1}$ ) than the $\mathrm{VO}_{2 \text { peak }}$ values of male folk dancers $[8,19$, 20]. The difference may be due to the dancers' international level and higher aerobic capacity requirement of dancesport compared to other dance forms [21]. Moreover, it is known that the type, intensity, and duration of exercise also affect biochemical parameters [2].

One of the exogenous resources causing oxidative stress is exercise. Muscle activity increased by the intensity and duration of exercise enhances energy production and consumption compared to the resting period; therefore, blood flow to the working muscle and $\mathrm{O}_{2}$ consumption also increase significantly. Although a certain increase in oxygen consumption during highly intense exercises consumes plasma antioxidants and raises free radical production, long-term low-intensity exercises have many beneficial physiological effects [1].

It is inevitable that oxidative stress occurs as a result of the imbalance between oxidants and antioxidants. However, oxidative damage can be brought under control, and its results can be minimised: reducing the intensity of exercise decreases free radical production which suppresses the antioxidant defence, and regular training both re-regulates erythrocyte antioxidant enzyme activity [22] and results in an increase in oxidative capacity [2].

The data obtained in this study indicate that regular low-intensity folk dance training can increase the capacity of the antioxidant system (TAC, $\mathrm{p}=0.000$; TOS, $\mathrm{p}=0.674$ ) and protect the body from the harmful effects of oxidants (tab. 5). These results are supported by the observed significant decrease in OSI $(\mathrm{p}=0.002)$ values. No published report is found in the literature on folk dance that the results of the current study could be compared against.

In only one study which investigated the effects of two different training types (basic techniques and rehearsals) of ballet dancers, both oxidative stress (lipid peroxides) and antioxidant system (glutathione metabolism) markers were found to be higher during basic technical exercise. This seems to be due to the fact that the stretching actions and short isometric contractions performed during technical work may cause ischemia. This situation may lead to both transient increases in muscle blood flow during relaxation and hyperaemia, and it may also 
result in the production of free radicals and lipid membrane damage [10].

It is known that regular exercise has a positive impact on lipid and carbohydrate metabolism, and the fitness level of the person and duration and intensity of the exercise are significant parameters affecting these changes. Among these parameters, both 'the frequency of the exercise' which is reported to be more effective [23] and 'the intensity of the exercise' are suggested to be more protective than the duration of the exercise [24]. The decrease in TC levels mostly depends on the decrease in LDL-C levels. It has been observed that serum apolipoprotein A-1 concentration increases, apolipoprotein B concentration decreases, and TG concentration may decrease to $20 \mathrm{mg} / \mathrm{dL}(0.23 \mathrm{mmol} / \mathrm{L})$ as a result of physical exercise. In general, exercise causes a less distinct biochemical response in fit individuals than in sedentary individuals [25].

In this study, it has been found that regular folk dance trainings do not have any positive significant effect on the blood lipid profile, but they increase LDL-C levels within reference ranges ( $p<0.015)$ (tab. 3). The low mean heart rate measured during the training sessions was probably the result of low exercise intensity (tab. 6), and this intensity was not enough to regulate blood lipid and lipoproteins [26]. The diet of the dancers, which was not controlled during the training period, could also be an explanation for the effects on the blood lipid profile we observed.

In a study on the Turkish population, it has been reported that physical activity in men and women over the age of 27 years has a negative correlation with TC $(\mathrm{r}=-127$; $\mathrm{p}<0.001)$, TG $(\mathrm{r}=$ $-0.095 ; \mathrm{p}<0.004)$, and LDL-C $(r=-0.122 ; \mathrm{p}<0.001)$ levels; however, it does not have a significant relationship with HDL-C levels [27]. In a meta-analysis study, it has been concluded that regular aerobic-type exercise results in a $6.3 \%$ decrease in TC, $10.1 \%$ decrease in LDL-C, and 5\% increase in HDL-C. These significant changes in lipids have been observed in individuals who lost weight during the exercise programme [25]. Although the $6.8 \%$ increase in HDL-C levels recorded in the current study was found not to be statistically significant, this can be considered as an important result, taking into account the finding that 'the risk of CHD decreases in a rate of $2-3 \%$ for each $1 \mathrm{mg}$ increase in HDL, independently from LDL' [28].

It has been assumed that muscular membrane permeability increases due to cell membrane damage and the depletion of energy resources and that skeletal muscle-based enzymes such as CK, LDH, AST, and ALT cause an increase in serum levels, described as micro-injury of muscle tissue, as a result of severe, and especially eccentric, exercise. It has even been stated that increased membrane permeability results in the production of free oxygen radical, and this process is realised through the ischemia-reperfusion mechanism [3].

Decreases in ALT $(-16.4 \% ; \mathrm{p}=0.028)$ and CK (89.1-74.5 $\mathrm{U} / \mathrm{L} ;-19.6 \% ; \mathrm{p}=0.069)$ and an increase in LDH $(10 \% ; \mathrm{p}=$ 0.023 ) activities were observed in the blood samples taken 2 days after the 12-week training period (tab. 4). It has also been reported that the magnitude of the intensity of exercise is more effective when it comes to cellular response to muscle damage than the duration of exercise [29] and that a submaximal exercise stimulus can have prophylactic and adaptational effects against muscle damage depending on the type of exercise [10]. The changes in our results could not be explained by previous findings, because enzyme activity was in the low limits of reference in both assessments, except for the study which found a decrease in CK (87.1-81.5 U/L) after 17 weeks of a ballet exercise programme [18].
A haemogram, that is a complete detailed record of the findings of a thorough examination of the blood, especially with reference to the numbers, proportions, and morphologic features of the formed elements [6], was performed before and after the training period, and all the parameters were found to be in normal reference ranges (tab. 2). The statistical decrease in $\mathrm{Hb}(\mathrm{g} /$ $\mathrm{dL}$ ) levels is likely related to red blood cells haemolysed in capillary vessels as a result of repeated mechanical micro-traumas during the exercise. The significant increase in MVC $(\mathrm{p}=0.000)$ probably occurred in order to compensate for the decrease in haemoglobin caused by the training. In parallel with our results, a decrease in RBC $\left(4.7-4.6 \mathrm{M} / \mathrm{mm}^{3} ; \mathrm{p}<0.01\right)$ and an increase in $\mathrm{Hb}(13.3-13.8 \mathrm{~g} / \mathrm{dL} ; \mathrm{p}<0.01)$ were observed after 17 weeks of participating in a ballet exercise programme. These results were interpreted as the effects of training on plasma volume expansion, RBC count reduction, and the fraction of the Hb to plasma volume relationship [18].

One of the limitations of this study is the absence of a control group to which the data of the group studied could be compared. This is due to the fact that we were unable to exclude dancers from the training routine in order to compose a control group. Other limitations of the study include the lack of control over the daily diet of the participants, use of the indirect method in physical and physiological measurements, and limited discussion due to the limited existing literature about the health effects of folk dances.

According to the data of the World Health Organization, the estimated global prevalence of physical inactivity is $17 \%$ in adults, and 1.9 million deaths a year are associated with physical inactivity [30]. This issue can be addressed, among others, by increasing the participation of individuals of all ages in folk dance activities which combine sport and music, as well having artistic and cultural value; they offer a systematic and wide range of movement forms and have physical, physiological, and psychological benefits [15].

\section{Conclusions}

As proven, among others, in the current study, regular folk dance training can have a positive effect on body fat, $\mathrm{VO}_{2 \text { peak }}$, blood total antioxidant capacity, and muscle damage in dancers. Therefore, folk dance should become popularised as a recreational activity in the community, and public awareness should be raised about health benefits of practising folk dances.

\section{Acknowledgements}

The assay is a summary of the first author's doctoral thesis. The authors would like to thank Asst. Prof. Dr. Faruk Turgay for his assistance in interpreting the results and Prof. Dr. Hande Orhan for her valuable contributions.

\section{Literature}

1. Ji L.L. (1999). Antioxidants and oxidative stress in exercise. Proceedings of the Society for Experimental Biology and Medicine 222, 283-292.

2. Finaud J., Lac G., Filaire E. (2006). Oxidative stress: Relationship with exercise and training. Sports Medicine 36, 327-358.

3. Taghiyar M., Darvishi L., Askari G., Feizi A., Hariri M., Mashhadi N.S. et al. (2013). The effect of vitamin C and E supplementation on muscle damage and oxidative stress in 
female athletes: A clinical trial. International Journal of Preventive Medicine 4(Suppl 1), S16-S23.

4. Yardan E. (2011). Serum paraoxonase, arylesterase, total antioxidant capacity, total oxidant capacity and PON1-Q192R phenotype relations in aortic and mitral valve diseases. Doctoral thesis, Dicle University Institution of Health Sciences, Diyarbakir. [in Turkish]

5. Esposito F., Impellizzeri F.M., Margonato V., Vanni R., Pizzini G., Veicsteinas A. (2004). Validity of heart rate as an indicator of aerobic demand during soccer activities in amateur soccer players. European Journal of Applied Physiology 93(1-2), 167-172.

6. Akgun N. (1989). Exercise Physiology II. İzmir: Başbakanlık Gençlik ve Spor Genel Müdürlüğü Yayınları. [in Turkish]

7. Ocak Y., Tortop Y. (2013). Examining the effects of folk dance exercises on some physical fitness parameters in women. Spor ve Performans Araștırmaları Dergisi 4(1), 46-54.

8. Gerek Z. (2007). Comparison of the physical fitness levels of folk dance and sports students using Eurofit. Ataturk University Beden Eğitimi ve Spor Bilimleri Dergisi 9(1), 11-21. [in Turkish]

9. Karacabey K., Durgun R., Sonmez E., Adilogulları I., Ozmerdivenli R. (2008). Determination of the anthropometric measurements of dancers from the Halay and Horon regions. Doğu Anadolu Bölgesi Araștırmaları 6(3), 56-61. [in Turkish]

10. Rodrigues-Krause J., Krause M., Cunha G.D.S., Perin D., Martins J.B., Alberton C.L. et al. (2014). Ballet dancers' cardiorespiratory, oxidative and muscle damage responses to classes and rehearsals. European Journal of Sport Science 14(3), 199-208.

11. Ratamess N.A., American College of Sports Medicine. (2012). ACSM's foundations of strength training and conditioning. Philadelphia, PA: Wolters Kluwer Health/Lippincott Williams \& Wilkins.

12. Dill D.B., Costill D.L. (1974). Calculation of percentage changes in volumes of blood, plasma, and red cells in dehydration. Journal of Applied Physiology 37, 247-248.

13. Unveren A. (2005). Determination of the physical activity level in the Turkish folk dance. Doctoral thesis, Gazi University Institution of Health Sciences, Ankara. [in Turkish]

14. Karakus S., Kılınç F. (2006). Posture and sportive performance. Kastamonu Egitim Dergisi 14(1), 309-322. [in Turkish]

15. Kurtisoglu B., Hatipoglu Ozcan G., Ozcan S. (2015). Obesity and dance: The case of folk dances. International Scientific Conference "Music and Dance", 6-8 May 2015, Diyarbakır, Turkey: Dicle University. [in Turkish]

16. Kaya I. (2011). Comparison of body fat percentage and the physiological properties of male folk dancers from the Zeybek and Horon groups. Selcuk University Beden Eğitimi ve Spor Bilimleri Dergisi 13(3), 378-382. [in Turkish]

17. McCord P., Nichols J., Patterson P. (1989). The effect of low impact dance training on aerobic capacity, submaximal heart rates and body composition of college-aged females. The
Journal of Sports Medicine and Physical Fitness 29(2), 184188.

18. da Silva C.C., Goldberg T.B.L., Soares-Caldeira L.F., Oliveira R.D.S., de Paula Ramos S., Nakamura F.Y. (2015). The effects of 17 weeks of ballet training on the autonomic modulation, hormonal and general biochemical profile of female adolescents. Journal of Human Kinetics 47(1), 61-71.

19. Maciejczyk M., Fec A. (2013). Evaluation of aerobic capacity and energy expenditure in folk dancers. Human Movement 14(1), 76-81.

20. Macura M., Pešić K., Đorđević-Nikić M., Stojiljković S., Dabović M. (2007). Morphological characteristics and functional abilities of an elite folk ensemble dancer. Physical Culture 61(1-2), 112-117.

21. Liiv H., Jürimäe T., Mäestu J., Purge P., Hannus A., Jürimäe J. (2014). Physiological characteristics of elite dancers of different dance styles. European Journal of Sport Science 14(suppl. 1), S429-S436.

22. Ji L.L. (1995). Exercise and oxidative stress: Role of the cellular antioxidant systems. Exercise and Sport Sciences Reviews 23, 135-166.

23. Kim J.R., Oberman A.L., Fletcher G.F. (2001). Effect of exercise intensity and frequency on lipid levels in men with coronary heart disease: Training level comparison trial. American Journal of Cardiology 87, 942-949.

24. Tanasescu M., Leitzmann M.F., Rimm E.B., Willett W.C., Stampfer M.J., Hu F.B. (2002). Exercise type and intensity in relation to coronary heart disease in men. The Journal of the American Medical Association 288, 1994-2000.

25. Gursoy S. (2008). Regular exercise effects on the total antioxidant capacity and serum lipid profile of students. Doctoral thesis, Inonu University Institution of Health Sciences, Malatya. [in Turkish]

26. American College of Sports Medicine. (1998). The recommended quantity and quality of exercise for developing and maintaining cardiorespiratory and muscular fitness, and flexibility in healthy adults. Medicine and Science in Sports and Exercise 30(6), 265-274.

27. Onat A. (2000). Physical activity in Turkish adults and its effects on the main risk factors. In A. Onat (ed.), TEKHARF: Heart Health, Heart Disease and Risk Profile in Turkish adults. Istanbul: Ohan Matbaacılık Ltd. [in Turkish]

28. Yuksel H. (2001). When should fibrates be used? Turk Kardiyoloji Dernegi Arsivi 29, 715-722. [in Turkish]

29. Semin I., Kayatekin M., Oktay G., Selamoglu S., Turgay F., Acarbay S. et al. (1993). The effect of 8-week football training on footballers' haematological parameters related to iron and body composition. Hacettepe Journal of Sports Sciences (4)3, 3-12. [in Turkish]

30. Arıkan I., Metintas S., Kalyoncu C. (2008). Comparison of two different methods of assessing the level of physical activity in young adults. Osmangazi Tip Dergisi 30(1), 19-28. [in Turkish]

Submitted: April 28, 2016

Acc epted: July 12, 2016 